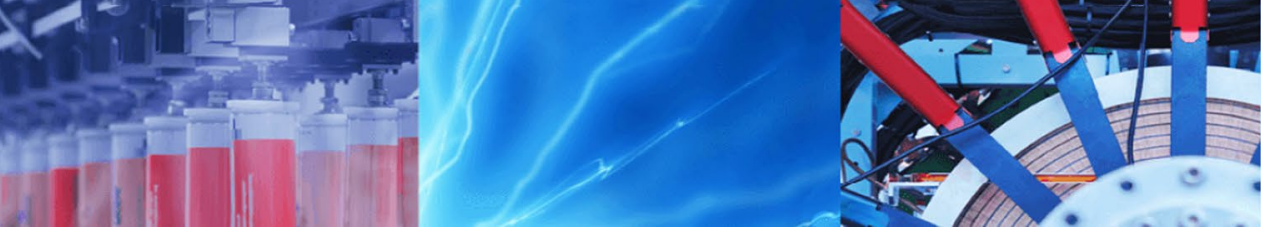

Research Article

\title{
Kinetics and mechanism of the solid-acid catalyzed one-pot conversion of D-fructose to 5, 5'-[oxybis(methylene)] bis[2-furaldehyde] in dimethyl sulfoxide
}

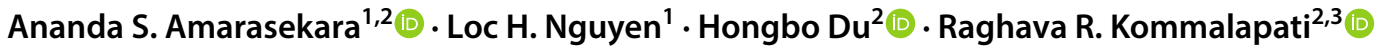

(c) Springer Nature Switzerland AG 2019

\begin{abstract}
The kinetics and the mechanism of Dowex 50WX8 catalyzed conversion of D-fructose to 5, 5'-[oxybis(methylene)]bis[2furaldehyde] via the intermediate 5-hydroxymethylfurfural was studied in DMSO. The first order rate constants for two step process was determined at 383 and $393 \mathrm{~K}$ by monitoring the concentrations of 5-hydroxymethylfurfural and 5 , 5 '-[oxybis(methylene)]bis[2-furaldehyde]. The activation energies for D-fructose to 5-hydroxymethylfurfural conversion and dimerization to 5, 5'-[oxybis(methylene)]bis[2-furaldehyde] were determined as 48.2 and $24.5 \mathrm{~kJ} \mathrm{~mol}^{-1}$. A detailed mechanism with four acid catalyzed dehydration steps is proposed for the one-pot conversion of $\mathrm{D}$-fructose to $5,5^{\prime}$-[oxybis(methylene)]bis[2-furaldehyde] based on ${ }^{1} \mathrm{H}$ NMR studies in DMSO- $d_{6}$ at $393 \mathrm{~K}$.
\end{abstract}

Keywords D-Fructose · 5, 5'-[oxybis(methylene)]bis[2-furaldehyde] $\cdot 5$-Hydroxymethylfurfural $\cdot$ Dowex 50WX8 $\cdot$ Solidacid catalyst

\section{Introduction}

The evolving interest in the use of renewable resources based feedstocks for the polymer and chemical industry has promoted the studies on a diversity of plant based compounds such as vegetable oil triglycerides [1], succinic acid [2], lactic acid [3, 4], 1,3-propanediol [5, 6], levulinic acid [7-9], 5-hydroxymethylfurfural (HMF) [10-12], 2,5 -furandicarboxylic acid or its derivatives $[13,14]$, and vanillin $[15,16]$. The furan derivatives furfural (FF) and HMF form an important sub-group in these renewable feedstocks as most of the abundant $\mathrm{C} 5$ and $\mathrm{C} 6$ monosaccharides can be dehydrated to these furans using inexpensive acid catalysts at moderate temperatures. Furfural is one of the earliest used renewable resource based feedstock in the polymer industry and Durite Plastics Inc. started the manufacture of phenol-furfural resins and plastic materials in the 1930's [17]. This may be due to the relatively easy preparation of furfural from hemicellulose rich biomass involving a mineral acid catalyzed aqueous phase process and distillation [18] as well as the hydrolytic stability of furfural. On the contrary, the production of the related C6 furan compound 5-hydroxymethylfurfural is much more challenging due to further transformations via a rehydration reaction giving levulinic acid and formic acid as well as polymerizations to humins [19].

Even though there are a number of challenges in preparation, isolation and storage of 5-hydroxymethylfurfural, this bifunctional furan has received significant interest as its derivatives such as oxidation products 2,5-furandicarboxaldehyde and 2,5-furandicarboxylic acid (FDCA) are attractive monomers for the synthesis of next generation renewable polymers [10, 20-25]. The dicarboxylic acid derivative FDCA is probably the most widely studied compound in the series. This symmetrical building block has been listed in a 2004 US Department of Energy National

\footnotetext{
$\triangle$ Ananda S. Amarasekara, asamarasekara@pvamu.edu | 'Department of Chemistry, Prairie View A\&M University, Prairie View, TX 77446, USA. ${ }^{2}$ Center for Energy and Environmental Sustainability, Prairie View A\&M University, Prairie View, TX 77446, USA. ${ }^{3}$ Department of Civil and Environmental Engineering, Prairie View A\&M University, Prairie View, TX 77446, USA.
}

SN Applied Sciences (2019) 1:964 | https://doi.org/10.1007/s42452-019-0994-2

Received: 30 March 2019 / Accepted: 26 July 2019 / Published online: 2 August 2019 
Renewable Energy Laboratory (NREL) report as one of the twelve key chemicals that can be subsequently converted to a variety of high-value bio-based chemicals and polymeric materials [26].

Since there are certain challenges in preparation and isolation of HMF, we have recently studied the possibility of in situ preparation of the more stable HMF dimer, avoiding the isolation of the unstable HMF as a way of producing an alternative symmetrical feedstock for polymer industry [27]. In our previous studies we have found that HMF dimer dialdehyde 5, 5'-[oxybis(methylene)] bis[2-furaldehyde] (OBFC, 1) shown in Fig. 1 can be produced in good yields by heating a concentrated solution of D-fructose at $383 \mathrm{~K}$ in DMSO with Dowex $50 \mathrm{WX} 8$ solid acid catalyst, without isolation of the intermediate HMF [27]. Furthermore, this dialdehyde was then converted to the dicarboxylic acid monomer, 5,5'-[oxybis(methylene)] bis[2-furancarboxylic acid] (2) using oxygen (1 atm.) and $5 \% \mathrm{Pt} / \mathrm{C}$ catalyst in $1.5 \mathrm{M}$ aqueous $\mathrm{NaOH}$ at room temperature in $98 \%$ yield [27] as shown in Fig. 1. The new dicarboxylic acid monomer can be considered as a renewable resources based alternative to terephthalic acid as demonstrated by the preparation of the polyesters with 1,2-ethanediol and 1,4-butanediol in $87-92 \%$ yield (Fig. 1). As a continuation of this research effort we have studied the kinetics and reaction mechanism of Dowex 50WX8 solid acid catalyzed one-pot conversion of $D$-fructose to $5,5^{\prime}$-[oxybis (methylene)]bis[2-furaldehyde] (OBFC, 1) in dimethyl sulfoxide. The understanding of the mechanism and kinetics data of the reaction are required in deciding optimum reaction conditions and this is especially important in the industrial scale production of OBFC. The kinetic data obtained in this study, rate constants and activation energies of reaction steps are useful to achieve the maximum D-fructose conversion, product yield, optimum reaction time and also to maintain the most desirable reaction temperature. In this publication we present the kinetics of this industrially useful OBFC preparation process as well as a reaction mechanism proposed on the basis of NMR studies carried out in deuterated DMSO medium.

\section{Experimental}

\subsection{Materials and instrumentation}

D-fructose (>99\%), Dowex 50WX8 (hydrogen form, $1.7 \mathrm{meq} / \mathrm{mL}$, 50-100 mesh), biphenyl (>99\%) and dimethyl sulfoxide were purchased from Aldrich Chemical Co. The $\mathrm{D}$-fructose samples were heated in a thermostated oil bath using a Cole-Parmer ML-04801-68 hot plate and plugin ML-04801-80 digital temperature controller with $\pm 0.1 \mathrm{~K}$ accuracy. ${ }^{1} \mathrm{H}$ NMR spectra were recorded in DMSO- $d_{6}$ on a Varian Mercury plus spectrometer operating at $400 \mathrm{MHz}$ and chemical shifts are given in ppm downfield from TMS $(\delta=0.00) .{ }^{13} \mathrm{C}$ NMR spectra in DMSO- $d_{6}$ were recorded on the same spectrometer operating at $100 \mathrm{MHz}$; chemical shifts were measured relative to DMSO- $d_{6}$ and converted to $\delta(T M S)$ using $\delta(D M S O)=39.51 \mathrm{ppm}$. The products were identified using Varian Saturn 2100T GC-MS and confirmed by co-injection of authentic samples. The quantitative analysis was carried out on a Varian 3900 GC, with a WCOT fused silica capillary column $(15 \mathrm{~m} \times 0.25 \mathrm{~mm})$, VF-1 ms stationary phase and FID detector, injector $250^{\circ} \mathrm{C}$, detector $300{ }^{\circ} \mathrm{C}$. The oven temperature was set at $200^{\circ} \mathrm{C}$ with a flow rate $2.0 \mathrm{~mL} / \mathrm{min}$. In the quantitative analysis, a standard curve was generated for each compound using Varian Star 6.2 Chromatographic Workstation software with the total ion current (TIC) peak area being correlated to the concentration of the compound in solution. The rate constants of the reactions were derived by fitting the HMF concentration changes along the reaction time with the aid of the toolbox cftool available in MATLAB. During the curve fittings, the nonlinear least squares method was used with the trust region algorithm, and the fitting robustness was improved by least absolute deviations.
Fig. 1 The oxidation of $5,5^{\prime}$-[oxybis(methylene)] bis[2-furaldehyde] (OBFC, 1) to $5,5^{\prime}$-[oxybis(methylene)] bis[2-furancarboxylic acid] (2) and synthesis of polyesters (3) by condensation with diols [27]. $\mathrm{a}=5 \% \mathrm{Pt} / \mathrm{C}, \mathrm{O}_{2}, 1 \mathrm{~atm}$., $1.5 \mathrm{M}$ aqueous $\mathrm{NaOH}, 23^{\circ} \mathrm{C}$, 48 h.; $b=\mathrm{SOCl}_{2}, \mathrm{DMF}, 80^{\circ} \mathrm{C}, 4 \mathrm{~h}$; $\mathrm{c}=1,2$-ethanediol or 1,4-butanediol, pyridine, 1,1,2,2-tetrachloroethane, $0-23^{\circ} \mathrm{C}, 12 \mathrm{~h}$

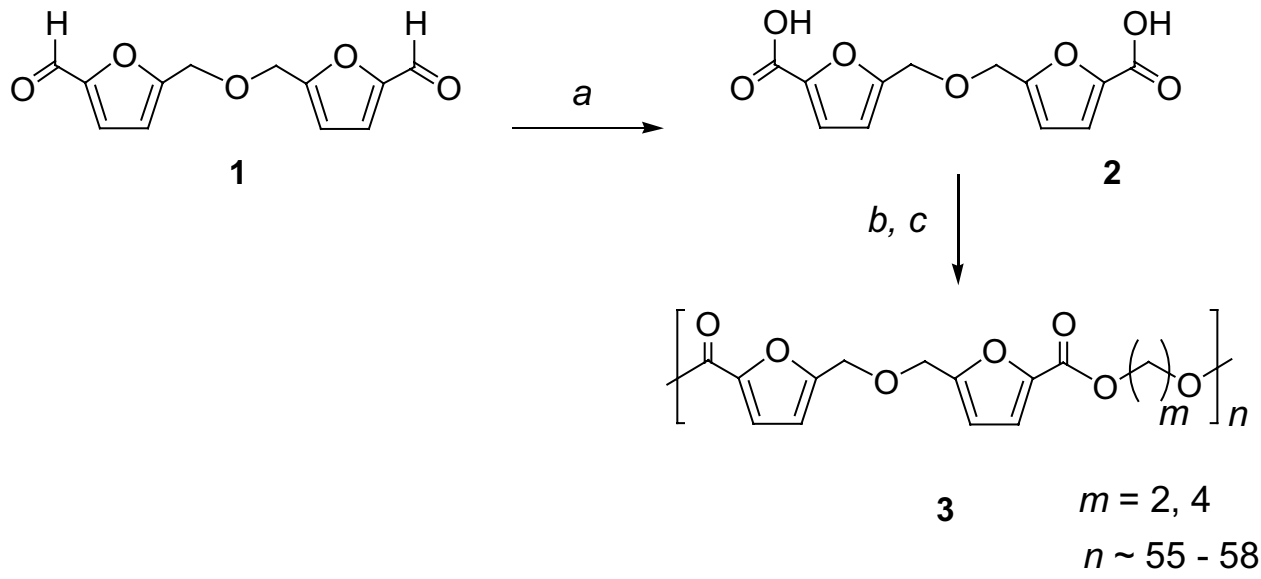




\subsection{Kinetics study of the solid-acid catalyzed one-pot conversion of $D$-fructose to 5 , 5'-[oxybis(methylene)]bis[2-furaldehyde] (OBFC, 1) in dimethyl sulfoxide}

A mixture of D-fructose $(5.00 \mathrm{~g}, 27.8 \mathrm{mmol})$, Dowex $50 \mathrm{WX} 8(0.50 \mathrm{~g})$ and internal standard biphenyl $(0.50 \mathrm{~g})$ in $10 \mathrm{~mL}$ of dimethyl sulfoxide was heated in an open boiling tube using an oil bath at $383.0 \pm 0.1 \mathrm{~K}$ for $15 \mathrm{~h}$ with magnetic stirring. The $0.10 \mathrm{~mL}$ test samples were withdrawn from the reaction mixture in 30 min intervals in the first $2 \mathrm{~h}$ and then at every hour afterwards. These $0.10 \mathrm{~mL}$ test samples were diluted with $1.00 \mathrm{~mL}$ of methanol before gas chromatography analysis. A standard series prepared by mixing known amounts of authentic HMF, OBFC and internal standard biphenyl was used in the preparation of the calibration plot. All the kinetic analysis was carried out in duplicate and the experiment was repeated at $393.0 \pm 0.1 \mathrm{~K}$. The conversion of $\mathrm{D}$-fructose to OBFC (1) through HMF (4) is shown in Fig. 2 and the average variations of molar concentrations of $\mathrm{HMF}$, OBFC with time for experiments carried out at $383.0 \pm 0.1$ and $393.0 \pm 0.1 \mathrm{~K}$ are shown in the plot in Fig. 3 .

\subsection{Mechanistic study of the solid-acid catalyzed conversion of D-fructose to 5 , 5'-[oxybis(methylene)]bis[2-furaldehyde] (OBFC, 1$)$ in dimethyl sulfoxide - $\mathrm{d} 6$}

A mixture of D-fructose ( $250 \mathrm{mg}, 1.39 \mathrm{mmol}$ ), Dowex $50 \mathrm{WX} 8(25 \mathrm{mg})$ and biphenyl $(25 \mathrm{mg})$ in $0.5 \mathrm{~mL}$ of dimethyl sulfoxide- $\boldsymbol{d}_{6}$ was prepared in an NMR tube. The compounds in NMR tube was thoroughly mixed using a vibrating mixture for $1.0 \mathrm{~min}$ and ${ }^{1} \mathrm{H} N M R(\mathrm{rd}=2 \mathrm{~s}, \mathrm{NS}=8)$ was recorded as baseline data $(t=0)$. Then the sample was heated in the thermostated oil bath at $393.0 \pm 0.1 \mathrm{~K}$ for $30 \mathrm{~min}$. After the heating period the reaction was quenched by immersing the NMR tube in ice-cold water for $3 \mathrm{~min}$ and then immediately transferred to the NMR spectrometer and ${ }^{1} \mathrm{H}$ NMR was recorded under conditions identical to the $t=0$ spectrum. Further spectra were recorded after heating for increasing time periods as described in the kinetics study procedure. The HMF intermediate and final product OBFC were identified by comparison with the reported spectra of these compounds recorded in the same solvent $\left(\right.$ DMSO- $\left.d_{6}\right)[27,28]$. A stack plot of a series of selected ${ }^{1} \mathrm{H}$ NMR spectra showing the formation of HMF intermediate first and then transformation to the final product OBFC is shown in Fig. 4. The

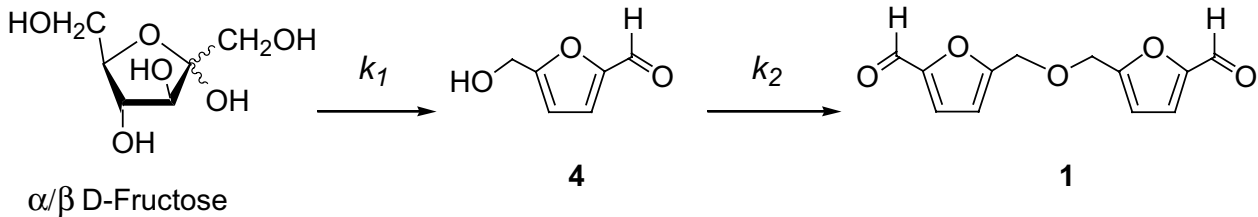

Fig. 2 The solid acid Dowex 50WX8 catalyzed transformations of $\alpha / \beta$ D-fructose to 5 -hydroxymethylfurfural $(H M F, 4)$ and then $H M F$ to 5 , 5'-[oxybis(methylene)]bis[2-furaldehyde] (OBFC, 1) in DMSO

Fig. 3 The changes in 5-hydroxymethylfurfural (HMF, 4) and oxybis(methylene)] bis[2-furaldehyde] (OBFC, 1) concentrations with time during the Dowex 50WX8 catalyzed transformation of $\alpha / \beta$ D-fructose to OBFC in DMSO. Experimental data from two experiments conducted at 383 and $393 \mathrm{~K}$ are shown

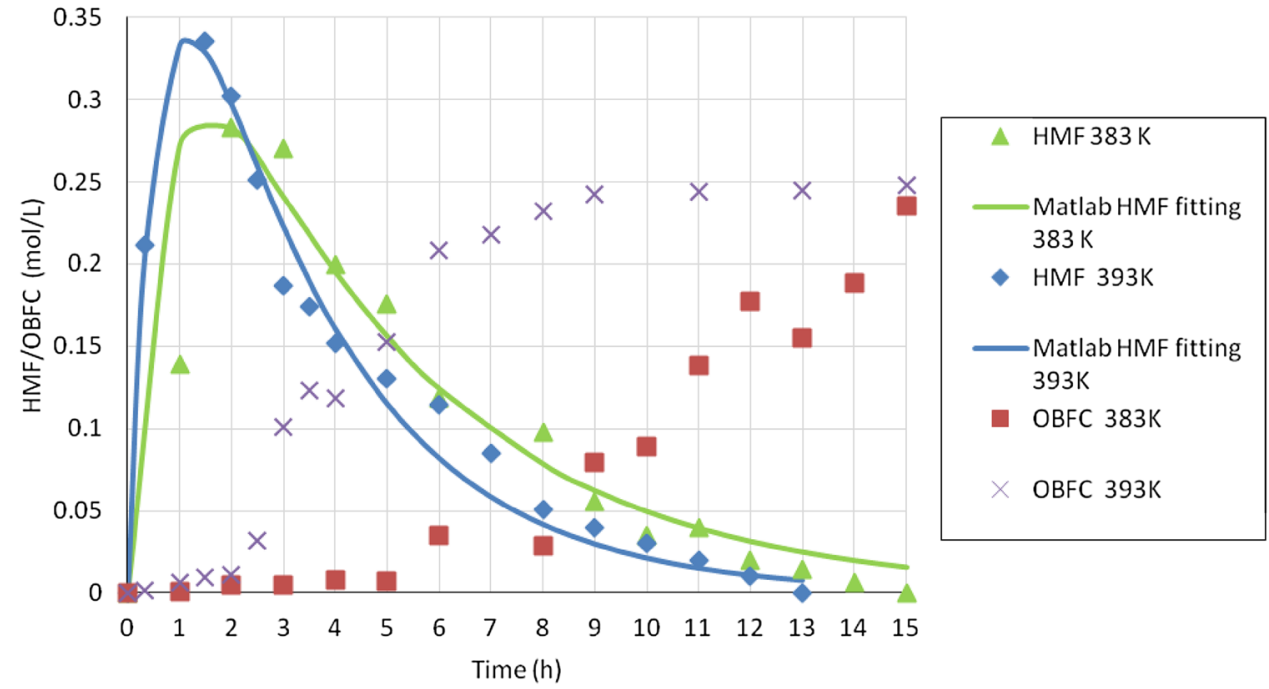

SN Applied Sciences A SPRINGER NATURE journa 
Fig. $4{ }^{1} \mathrm{H}$ NMR spectra of $\alpha / \beta$ $D$-fructose, Dowex mixture in DMOS- $d_{6}$ before heating $(\mathrm{t}=0)$ and after $0.5,1,3,6$ and $15 \mathrm{~h}$ heating at $393 \mathrm{~K}$. The $\mathrm{t}=1,3$, 6 and $15 \mathrm{~h}$ spectra are shown with increasing $0.2 \mathrm{ppm}$ shift to the left for clarity

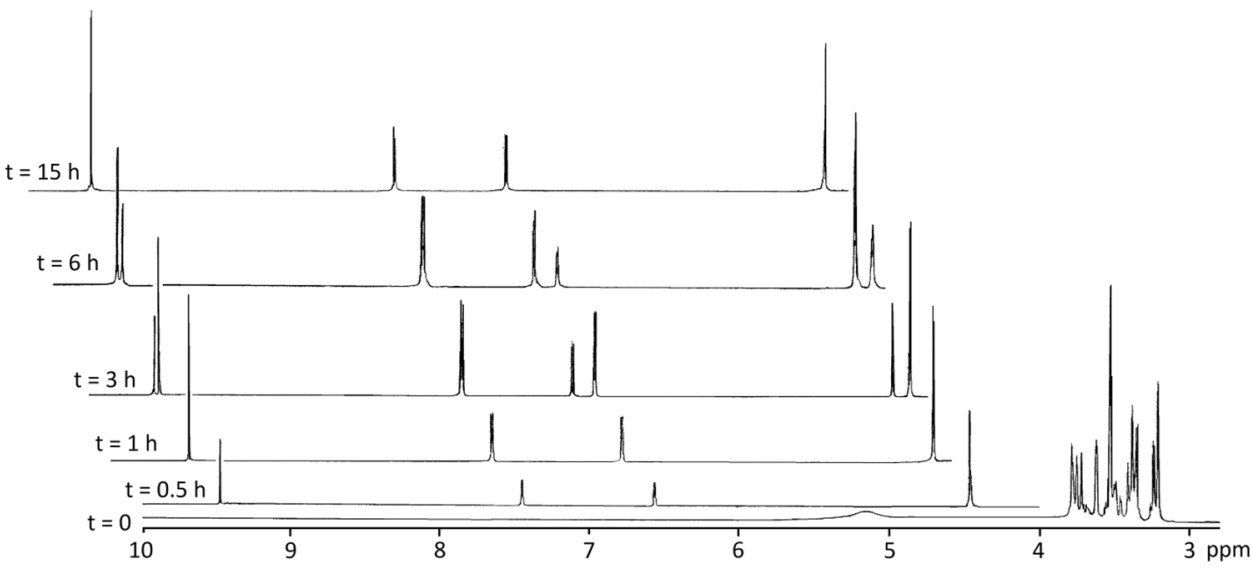

mechanism proposed on the basis of this study is shown in Fig. 5.

\section{Results and discussion}

\subsection{Kinetics study of the solid-acid catalyzed one-pot conversion of $D$-fructose to 5 , 5'-[oxybis(methylene)]bis[2-furaldehyde] (OBFC, 1) in dimethyl sulfoxide}

In this work we have studied the kinetics of the solid-acid catalyzed one-pot two step conversion of D-fructose to 5 , 5 '-[oxybis (methylene)]bis[2-furaldehyde] (OBFC, 1) via intermediate formation of HMF (4) as shown in Fig. 2. The changes in molar concentrations of HMF and OBFC with time for the two reactions carried out at 383 and $393 \mathrm{~K}$ are shown in Fig. 3 . These plots suggests that the two step process follows a consecutive, first order reaction kinetics [29]. In addition, first order reaction kinetics have been reported in analysis of similar acid catalyzed dehydrations [30, 31]. Therefore, the following kinetic Eqs. (1-7) can be derived for the acid catalyzed conversion of D-fructose to 5, 5'-[oxybis(methylene)] bis[2-furaldehyde] in dimethyl sulfoxide [29].

$$
A=D \text {-fructose, } B=H M F \text { and } C=O B F C
$$

$A \stackrel{k 1}{\rightarrow} B \stackrel{k 2}{\rightarrow} \frac{1}{2} C$

$\frac{d[A]}{d t}=-\mathrm{k}_{1}[\mathrm{~A}]$

$\frac{d[B]}{d t}=\mathrm{k}_{1}[\mathrm{~A}]-\mathrm{k}_{2}[\mathrm{~B}]$

$\frac{d[C]}{d t}=-\mathrm{k}_{2}[\mathrm{~B}]$
Fig. 5 The proposed mechanism for Dowex $50 \mathrm{WX} 8$ catalyzed conversion of $\alpha / \beta$ D-fructose to 5 , 5 '-[oxybis(methylene)]bis[2furaldehyde] (OBFC, 1) via the HMF (4) intermediate in DMSO

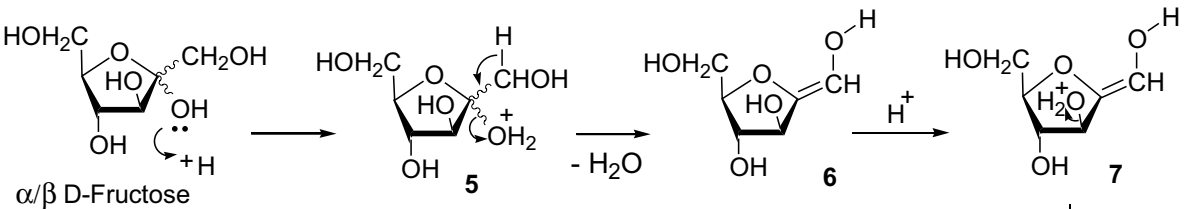
$\alpha / \beta$ D-Fructose

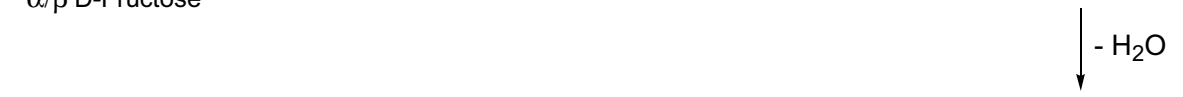

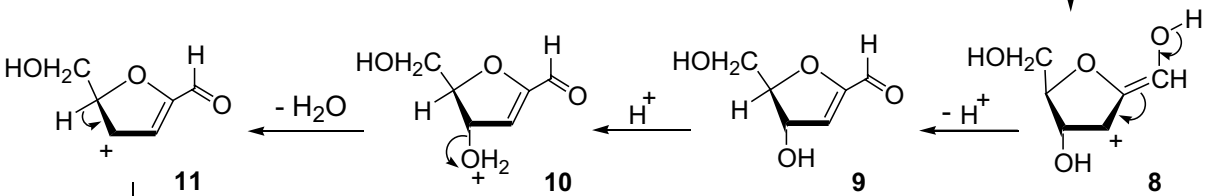<smiles></smiles>

10

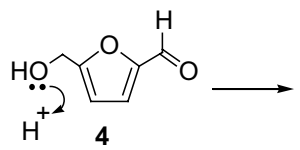<smiles>O=Cc1ccc(C=[OH+])o1</smiles><smiles>O=Cc1ccc(COCc2ccc(C=O)o2)o1</smiles> 
Table 1 The first order rate constants k1, k2 for solid-acid catalyzed one-pot conversion of $\alpha / \beta$ D-fructose to 5,5 '-[oxybis(methylene)] bis[2-furaldehyde] $(\mathrm{OBFC}, 1)$ via HMF (4) in dimethyl sulfoxide at 383 and $393 \mathrm{~K}$

\begin{tabular}{lll}
\hline Temperature $(\mathrm{K})$ & $\mathrm{k}_{1}\left(\mathrm{~h}^{-1}\right)$ & $\mathrm{k}_{2}\left(\mathrm{~h}^{-1}\right)$ \\
\hline 383 & 0.229 & 1.416 \\
393 & 0.338 & 1.722 \\
\hline
\end{tabular}

Table 2 The activation energies (Ea) and pre-exponential factors (A) for the two reaction steps: solid acid catalyzed conversion of $a / \beta$ D-fructose to 5 -hydroxymethylfurfural (HMF) and then HMF to $5,5^{\prime}$-[oxybis(methylene)]bis[2-furaldehyde] (OBFC) in dimethyl sulfoxide

\begin{tabular}{lll}
\hline Reaction step & Ea $\left(\mathrm{kJ} \mathrm{mol}^{-1}\right)$ & $\begin{array}{l}\text { Pre-expo- } \\
\text { nential } \\
\text { factor }(\mathrm{A})\end{array}$ \\
\hline D-Fructose to HMF & 48.2 & $8.7 \times 10^{5}$ \\
HMF to OBFC & 24.5 & $3.1 \times 10^{3}$ \\
\hline
\end{tabular}

at $\mathrm{t}=0[\mathrm{~A}]=[\mathrm{A}]_{0}$ and $[\mathrm{B}]=[\mathrm{C}]=0$.

at all times $[A]+[B]+2[C]=[A]_{0}$.

Integration of the three differential equations gives solutions:

$[A]=[A]_{0} \exp \left(-k_{1} t\right)$

$[\mathrm{B}]=\frac{k_{1}}{k_{2}-k_{1}}[\mathrm{~A}]_{0}$

$[C]=\left\{1+\frac{k_{1} \exp \left(-k_{2} t\right)-k_{2} \exp \left(-k_{1} t\right)}{k_{2}-k_{1}}\right\} \frac{1}{2}[A]_{0}$

The MATLAB curve fittings for the experimentally determined HMF concentration changes in the two reactions carried out at 383 and $393 \mathrm{~K}$ are shown in Fig. 3. These curve fittings gave reasonable goodness of fit $R^{2}$ values 0.9748 and 0.9811 for experimental data sets at 383 and $393 \mathrm{~K}$ respectively. The first order rate constants $\mathrm{k} 1$ and $\mathrm{k} 2$ at the two temperatures were calculated using MATLAB simulation and these values are shown in Table 1. The activation energies $(\mathrm{Ea})$ and pre-exponential factor $(\mathrm{A})$ values for the two reaction steps: solid acid catalyzed conversion of $\mathrm{D}$-fructose to 5-hydroxymethylfurfural (HMF) and then HMF to 5, 5'-[oxybis(methylene)]bis[2-furaldehyde] were calculated by applying the rate constants in Arrhenius equation and these values are shown in Table 2.

A few research groups have studied the dehydration of D-fructose or D-glucose to HMF with and without added catalysts [30,32]. For instance $Q u$ et al. has reported an activation energy of $55.77 \mathrm{~kJ} \mathrm{~mol}^{-1}$ and the pre-exponential factor as $1.6 \times 10^{4} \mathrm{~min}^{-1}$ for the 1 -hydroxyethyl-3-methylimidazolium tetrafluoroborate ionic liquid catalyzed dehydration of D-glucose in DMSO [32]. In another example Lee and co-workers have reported Ea values 67.50 and $80.05 \mathrm{~kJ} \mathrm{~mol}^{-1}$ for catalyzed and uncatalyzed reactions; where $\mathrm{D}$-fructose was dehydrated to HMF in an ionic liquid- $\mathrm{CrCl}_{2}$ system, with and without a bi-functional mesoporous silica nanoparticle (MNS) catalyst [30]. In comparison the presented Dowex $50 \mathrm{WX} 8$ catalyzed process showed an activation energy of $48.2 \mathrm{~kJ} \mathrm{~mol}^{-1}$; which is lower than bi-functional mesoporous silica nanoparticle (MNS) catalyzed process, indicating the effectiveness of strong Brønsted acidity of Dowex 50WX8 in DMSO. As far as we are aware there are no reports on activation energy determinations for the HMF to OBFC conversion. Therefore, our Ea determination of $24.5 \mathrm{~kJ} \mathrm{~mol}^{-1}$ is the first reported value for this acid catalyzed dehydrative ether formation. It is interesting to note that Casas et al. has reported an Ea value of $110 \mathrm{~kJ} \mathrm{~mol}^{-1}$ for the liquid phase dehydration of 1 -octanol to di- ${ }^{n-}$ octyl ether over Amberlyst 70 catalyst in 1,4-dioxane [31]. This significant difference may be due to facile dehydrative ether formation from HMF due to benzylic like $-\mathrm{CH}_{2} \mathrm{OH}$ group in $\mathrm{HMF}$, in contrast to aliphatic, primary - $\mathrm{OH}$ in 1-octanol, as well as the favorable stabilization of carbonium ions and protonated intermediates in DMSO medium.

\section{2 ${ }^{1} \mathrm{H}$ NMR mechanistic study of the solid-acid catalyzed conversion of $D$-fructose to 5 , 5'-[oxybis(methylene)]bis[2-furaldehyde] (OBFC, 1) in dimethyl sulfoxide-d6}

The mechanistic study using NMR spectroscopy was carried out in conditions similar to the kinetic study, using DMSO- $d_{6}$ as the solvent. The experiment was carried out at $393 \mathrm{~K}$ as reaction is faster and gave a higher yield at this temperature and a representative set of ${ }^{1} \mathrm{H}$ NMR spectra from this experiment are shown in Fig. 4. The baseline spectrum $(t=0)$ was recorded in the $D$-fructose Dowex 50 WX8 catalyst mixture in DMSO- $d_{6}$ before heating. This spectrum shows the hydroxyl groups of D-fructose as a broad peak around 5.0-5.3 ppm due to fast exchange of hydroxyl protons with $-\mathrm{SO}_{3} \mathrm{H}$ acidic H's in Dowex 50WX8. This type of carbohydrate -OH peak broadening in DMSO is well known where strong interactions are possible with Brønsted acids with multiple acidic sites [33]. The spectrum recorded after heating $30 \mathrm{~min}$ at $393 \mathrm{~K}$ showed four small peaks at $4.47(\mathrm{~s}), 6.54(\mathrm{~d}, \mathrm{~J}=3.6 \mathrm{~Hz}), 7.41(\mathrm{~d}, \mathrm{~J}=3.6 \mathrm{~Hz})$ and 9.46 (s) ppm due to the formation of HMF [28]. The $\mathrm{t}=1 \mathrm{~h}$ spectrum showed growth in these peaks, indicating further increase in concentration of HMF. However, in contrary to our earlier mechanistic study on dehydration of D-fructose in DMSO without an added acid catalyst 
[28] no peaks were observed due to the formation of other intermediates. In an earlier study we have identified $(4 R, 5 R)$-4-hydroxy-5-hydroxymethyl-4,5-dihydrofuran-2-carbaldehyde (9 in Fig. 5) as a key intermediate in the dehydration of D-fructose to HMF without an added acid catalyst [28]. Even though this intermediate is not observed in the present case, we believe that this intermediate (9) is formed, and then undergoes a fast dehydration under the strongly acidic conditions present in this reaction as shown in Fig. 5. Further heating of the sample for a total time of $3 \mathrm{~h}$ showed the dehydrative ether formation of HMF as indicated by a new set of small peaks at 4.59 (s), $6.73(\mathrm{~d}, \mathrm{~J}=3.6 \mathrm{~Hz}), 7.44(\mathrm{~d}, \mathrm{~J}=3.6 \mathrm{~Hz})$ and $9.55(\mathrm{~s})$ ppm corresponds to OBFC (Fig. 4). In prolonged heating, the peaks due to OBFC showed continuous growth at the expense of HMF peaks as shown in the $t=6 \mathrm{~h}$ spectrum. The HMF peaks finally disappeared after $15 \mathrm{~h}$ showing the complete conversion of HMF to OBFC. A detailed mechanism is proposed where sulfonic acid groups of Dowex $50 \mathrm{WX} 8$ act as the catalyst in dehydrations as shown in Fig. 5. First the protonation of $\mathrm{C} 2$ hydroxyl group of $\mathrm{D}$-fructose gives the intermediate $\mathbf{5}$, leading to the enol $\mathbf{6}$ after a water elimination. Secondly, the C3 hydroxyl group protonation of $\mathbf{6}$ gives 7; the dehydration of this intermediate results the carbonium ion $\mathbf{8}$ and this E1 type elimination can lead to the possible intermediate 9 . Next the elimination of a third water molecule via intermediates $\mathbf{1 0}$ and $\mathbf{1 1}$ will give the stable 5-hydroxymethylfurfural (4). In the last step, the protonated HMF (12) may react with a second molecule of HMF in a nucleophilic substitution reaction furnishing the final product 5, 5'-[oxybis(methylene)]bis[2-furaldehyde] (1) as shown in Fig. 5.

\section{Conclusion}

In conclusion, we have determined the activation energies for the two steps in consecutive reaction process in the Dowex 50WX8 catalyzed conversion of D-fructose to 5, 5'-[oxybis(methylene)]bis[2-furaldehyde] via the intermediate product 5-hydroxymethylfurfural. The activation energies for D-fructose to 5-hydroxymethylfurfural conversion and dimerization of 5-hydroxymethylfurfural to 5, 5'-[oxybis(methylene)]bis[2-furaldehyde] were determined as 48.2 and $24.5 \mathrm{~kJ} \mathrm{~mol}^{-1}$ respectively. A detailed mechanism with four acid catalyzed dehydration steps is proposed for the one-pot conversion of D-fructose to 5 , $5^{\prime}$-[oxybis (methylene)]bis[2-furaldehyde] by ${ }^{1} \mathrm{H}$ NMR studies in DMSO- $d_{6}$ at $393 \mathrm{~K}$. Interestingly, the intermediate (4R,5R)-4-hydroxy-5-hydroxymethyl-4,5-dihydrofuran2-carbaldehyde identified in an earlier uncatalyzed reaction was not observed in the Dowex 50WX8 catalyzed dehydration of D-fructose to HMF, probably due to a fast dehydration of this intermediate under strongly acidic catalytic conditions in this reaction.

Acknowledgements We thank NSF Grants CBET-1336469, CBET1704144, HRD-1036593, and USDA Grant CBG-2010-38821-21569 for financial support.

\section{Compliance with ethical standards}

Conflict of interest The authors declare that they have no conflict of interest.

\section{References}

1. Adekunle KF (2015) A review of vegetable oil-based polymers: synthesis and applications. Open J Polym Chem 5(3):34

2. Delhomme C, Weuster-Botz D, Kühn FE (2009) Succinic acid from renewable resources as a $C 4$ building-block chemicala review of the catalytic possibilities in aqueous media. Green Chem 11(1):13-26

3. Martinez FAC, Balciunas EM, Salgado JM, González JMD, Converti A, de Souza Oliveira RP (2013) Lactic acid properties, applications and production: a review. Trend Food Sci Technol 30(1):70-83

4. Maharana T, Pattanaik S, Routaray A, Nath N, Sutar AK (2015) Synthesis and characterization of poly (lactic acid) based graft copolymers. React Funct Polym 93:47-67

5. Achilias DS, Bikiaris DN (2015) Synthesis, properties and mathematical modeling of biodegradable aliphatic plyesters based on 1, 3-propanediol and dicarboxylic acids. In: Fakirov S (ed) Biodegradable polyesters. Wiley-VCH, Weinheim, pp 73-108

6. Lee $C$, Aroua $M$, Daud $W$, Cognet $P$, Pérès-Lucchese $Y$, Fabre $P$, Reynes O, Latapie $L$ (2015) A review: conversion of bioglycerol into 1, 3-propanediol via biological and chemical method. Renew Sustain Energy Rev 42:963-972

7. Pileidis FD, Titirici MM (2016) Levulinic acid biorefineries: new challenges for efficient utilization of biomass. Chemsuschem 9:562-582

8. Amarasekara AS, Animashaun MA (2016) Acid catalyzed competitive esterification and ketalization of levulinic acid with 1,2 and 1,3-diols: the effect of heterogeneous and homogeneous catalysts. Catal Lett 146:1819-1824

9. Lasprilla AJ, Martinez GA, Lunelli BH, Jardini AL, Maciel Filho $R$ (2012) Poly-lactic acid synthesis for application in biomedical devices: a review. Biotechnol Adv 30(1):321-328

10. Amarasekara AS (2011) 5-Hydroxymethylfurfural based polymers. In: Mittal V (ed) Renewable polymers, synthesis, processing and technology, 1st edn. Wiley-Scrivener, Salem

11. Gandini A (2010) Furans as offspring of sugars and polysaccharides and progenitors of a family of remarkable polymers: a review of recent progress. Polym Chem 1(3):245-251

12. Gandini A, Lacerda TM (2015) From monomers to polymers from renewable resources: recent advances. Progress Polym Sci 48:1-39

13. Gandini A, Silvestre AJD, Neto CP, Sousa AF, Gomes M (2009) The furan counterpart of polyethylene terephthalate: an alternative material based on renewable resources. J Polym Sci Part A: Polym Chem 47(1):295-298

14. Gandini A (2008) Polymers from renewable resources: a challenge for the future of macromolecular materials. Macromolecules 41(24):9491-9504 
15. Amarasekara AS, Wiredu B, Razzaq A (2012) Vanillin based polymers: I. An electrochemical route to polyvanillin. Green Chem 14(9):2395-2397

16. Amarasekara AS, Razzaq A (2012) Vanillin based polymers IIsynthesis of Sciff base polymers of divanillin and their chelation with metal ions. ISRN Polym Sci 2012 Article ID 532171

17. Karl VG, Novotny EE (1943) Art of preparing derivatives of anacardic material. US Patent, US2253088A

18. Brownlee HJ, Miner CS (1929) Process of manufacturing furfural. US Patents, US1735084A

19. Kuster B (1990) 5-Hydroxymethylfurfural (HMF): a review focussing on its manufacture. Starch-Stärke 42(8):314-321

20. Amarasekara AS, Green D, McMillan E (2008) Efficient oxidation of 5-hydroxymethylfurfural to 2,5-diformylfuran using Mn(III)salen catalysts. Catal Commun 9(2):286-288

21. Sousa AF, Vilela C, Fonseca AC, Matos M, Freire CS, Gruter G-JM, Coelho JF, Silvestre AJ (2015) Biobased polyesters and other polymers from 2, 5-furandicarboxylic acid: a tribute to furan excellency. Polym Chem 6(33):5961-5983

22. Amarasekara AS, Green D, Williams LD (2009) Renewable resources based polymers: synthesis and characterization of 2,5-diformylfuran-urea resin. Eur Polym J 45(2):595-598

23. Hui Z, Gandini A (1992) Polymeric schiff bases bearing furan moieties. Eur Polym J 28(12):1461-1469

24. Gomes M, Gandini A, Silvestre AJ, Reis B (2011) Synthesis and characterization of poly (2, 5-furan dicarboxylate) $s$ based on a variety of diols. J Polym Sci Part A: Polym Chem 49(17):3759-3768

25. Grosshardt O, Fehrenbacher U, Kowollik K, Tübke B, Dingenouts $N$, Wilhelm M (2009) Synthese und Charakterisierung von polyestern und polyamiden auf der basis von Furan-2, 5-dicarbonsäure. Chem-Ing-Tech 81(11):1829-1835

26. Werpy T, Petersen G, Aden A, Bozell J, Holladay J, White J, Manheim A, Eliot D, Lasure L, Jones S (2004) Top value added chemicals from biomass. volume 1 : results of screening for potential candidates from sugars and synthesis gas. DTIC Document
27. Amarasekara AS, Nguyen LH, Okorie NC, Jamal SM (2017) A two-step efficient preparation of a renewable dicarboxylic acid monomer 5,5'-[oxybis(methylene)]bis[2-furancarboxylic acid] from $D$-fructose and its application in polyester synthesis. Green Chem 19:1570-1575

28. Amarasekara AS, Williams LD, Ebede CC (2008) Mechanism of the dehydration of $\mathrm{D}$-fructose to 5-hydroxymethylfurfural in dimethyl sulfoxide at $150{ }^{\circ} \mathrm{C}$ : an NMR study. Carbohydr Res 343(18):3021-3024

29. Ball D (1998) Kinetics of consecutive reactions: first reaction, first-order; second reaction, zeroth order. J Chem Educ 75(7):917

30. Lee $Y-Y$, Wu KC-W (2012) Conversion and kinetics study of fructose-to-5-hydroxymethylfurfural (HMF) using sulfonic and ionic liquid groups bi-functionalized mesoporous silica nanoparticles as recyclable solid catalysts in DMSO systems. Phys Chem Chem Phys 14(40):13914-13917

31. Casas C, Bringué R, Fité C, Iborra M, Tejero J (2017) Kinetics of the liquid phase dehydration of 1-octanol to di-n-octyl ether on Amberlyst 70. AIChE J 63(9):3966-3978

32. Qu Y, Huang C, Song Y, Zhang J, Chen B (2012) Efficient dehydration of glucose to 5 -hydroxymethylfurfural catalyzed by the ionic liquid,1-hydroxyethyl-3-methylimidazolium tetrafluoroborate. Bioresour Technol 121:462-466

33. Kobayashi H, Yabushita M, Hasegawa J-y, Fukuoka A (2015) Synergy of vicinal oxygenated groups of catalysts for hydrolysis of cellulosic molecules. J Phys Chem C 119(36):20993-20999

Publisher's Note Springer Nature remains neutral with regard to jurisdictional claims in published maps and institutional affiliations. 